\title{
ANALISIS PENGUKURAN KINERJA DIVISI IT MENGGUNAKAN IT BALANCED SCORECARD PADA PT. XYZ
}

\author{
Edi Gunawan \\ Program Studi Magister Manajemen Universitas Tarumanagara \\ edzgun@gmail.com
}

\begin{abstract}
This research is to measure Information Technology performance in a company using IT Balanced Scorecard. Currently at PT. XYZ, there is no measurement of IT performance to know the contribution of IT department, so that the author plans to develop the IT Balanced Scorecard to measure the performance of IT department. IT Balanced Scorecard that has four perspectives is very well used to formulate IT Strategic targets that support the company' strategic goals and measure IT performance. Plan to implement the IT Balanced Scorecard can be done by data collection, interview, and questionnaries, so we can know the initial conditions at IT department. With this analysis, can be seen directly the support of IT department to company strategic plan, get new standard for KPI (Key Performance Indicator) so in the future, performance improvement can be measured better and get seven strategic objectives used by the IT department.
\end{abstract}

Keywords : Performance Measurement, IT Balanced Scorecard, Strategic Map, Key Performance Indicator

\section{PENDAHULUAN}

Pada saat ini, teknologi sudah menjadi kebutuhan primer bagi kehidupan manusia. Sebagian besar kegiatan manusia seperti komunikasi, transportasi, industri, ilmu kedokteran dan lainnya dilakukan dengan bantuan teknologi. Teknologi digunakan sebagai sarana untuk pertukaran informasi, mempermudah produksi kebutuhan, mempermudah dalam bepergian dari satu tempat ke tempat lain dan lain-lain. Oleh sebab itu, teknologi tidak dapat dipisahkan begitu saja dari kehidupan manusia.

Setiap tahunnya banyak teknologi baru yang diciptakan dan dikembangkan untuk memperbaiki teknologi yang sudah ada ataupun inovasi di dalam perkembangan teknologi. Inovasi yang baru diharapkan dapat membantu manusia dalam melakukan pekerjaannya serta mendukung kegiatan operasional perusahaan dalam mencapai tujuan perusahaan, baik tujuan jangka pendek maupun tujuan jangka panjang.

Penerapan IT ke dalam sebuah perusahaan tidak gampang, karena selain membutuhkan biaya yang cukup besar, juga harus membutuhkan pengguna (user) yang dapat mengoperasikan IT tersebut. Perusahaan yang menerapkan IT ke dalam perusahaan sudah pasti menginginkan investasi yang dilakukan tersebut dapat memberikan keuntungan, dampak, serta hasil yang lebih baik dari sebelumnya.

Muncul masalah baru setelah menerapkan IT ke dalam perusahaan, yaitu bagaimana cara untuk mengukur kinerja IT yang diterapkan agar IT tersebut dapat mempengaruhi dan mengembangkan perusahaan. Mengukur kinerja IT bertujuan untuk mengetahui apakah penerapan IT ke dalam perusahaan berhasil sesuai harapan atau tidak serta apa pengaruh IT tersebut untuk perusahaan. Setelah mengetahui kinerja IT, perusahaan juga dapat membuat strategi selanjutnya agar IT yang diterapkan menjadi semakin baik. Pengukuran ini merupakan suatu hal yang penting karena kita dapat mengukur pencapaian visi dan misi perusahaan, problem solving, serta dapat memaksimalkan alokasi sumber daya perusahaan dengan tepat. 
Penyusunan perangkat kerja perusahaan yang efektif dan signifikan dengan kondisi persaingan bisnis saat ini dilakukan dengan menggunakan kerangka IT Balanced Scorecard (IT BSC) yang dicetus oleh Grembergen dan Bruggen (1998), di mana sebenarnya pendekatan ini tetap berdasarkan turunan dari Balanced Scorecard (BSC) yang dikemukakan oleh Kaplan dan Norton (1992). Dengan IT Balanced Scorecard, kinerja perusahaan tidak hanya diukur dari keuntungan yang diperoleh secara finansial saja, tetapi juga mempertimbangkan proses internal serta kepuasan dan peningkatan kompetensi dari setiap pegawai. Dengan demikian perusahaan dapat lebih memastikan kinerja yang baik untuk masa yang akan datang.

IT Balanced Scorecard akan mengukur kinerja Divisi IT berdasarkan empat perspektif yang ada, yaitu Perspektif Kontribusi Perusahaan, Perspektif Orientasi User, Perspektif Operasional, dan perspektif Orientasi Masa Depan.

PT. XYZ sudah menerapkan Teknologi Informasi dan menyadari bahwa perusahaan perlu untuk perbaikan secara internal terlebih dahulu, baik dari segi infrastruktur, skill karyawan, dan lainnya. Selain meningkatkan kinerja dari segi teknis, Divisi IT juga harus dapat melakukan analisa terhadap hal-hal yang diperlukan untuk mendukung kegiatan operasional perusahaan.

Oleh karena itu, perusahaan harus melakukan analisa serta pengukuran terhadap kinerja dari Divisi IT, apakah dampak yang diberikan memang ada, atau tidak ada terhadap perusahan. Dengan penelitian ini diharapkan dapat memberikan gambaran kinerja Divisi IT pada PT. XYZ dan juga sebagai rekomendasi perbaikian kinerja Divisi IT ke depannya.

\section{TINJAUAN PUSTAKA}

Kinerja. Mulyadi (2007) mendefinisikan kinerja sebagai keberhasilan personel, tim, atau unit organisasi dalam mewujudkan sasaran strategik yang telah ditetapkan sebelumnya dengan perilaku yang diharapkan.

Keberhasilan pencapaian strategik perlu diukur. Itulah sebabnya sasaran strategik yang menjadi basis pengukuran kinerja perlu ditentukan ukurannya, dan ditentukan inisiatif strategik untuk mewujudkan sasaran tersebut. Sasaran strategik beserta ukurannya kemudian digunakan untuk menentukan target yang akan dijadikan basis penilaian kinerja, untuk menentukan penghargaan yang akan diberikan kepada personel, tim, atau unit organisasi.

Pengukuran Kinerja. Mulyadi (2007) mendefinisikan pengukuran kinerja sebagai penentu secara periodic efektivitas operasional suatu organisasi, bagian organisasi, dan karyawan berdasarkan sasaran, standard dan kriteria yang telah ditetapkan sebelumnya.

Balanced Scorecard pertama kali dikembangkan oleh Kaplan dan Norton pada tingkat enterprise. Pendekatan ini digunakan secara ekstensif pada bisnis, industry, dan organisasi yang tidak mengejar laba di seluruh dunia untuk menyelarskan aktifitas bisnis dengan visi dan strategi organisasi, meningkatkan komunikasi internal dan eksternal, dan memantau kinerja organisasi terhadap tujuan strategis.

Menurut Kaplan dan Norton (2009, p.71) mengenai Balanced Scorecard : "...a set of measures that give top managers a fast but comprehensive view of the business...includes financial measures that tell the result of actions already taken...complements the financial measures with operational measures on customers satisfaction, internal process, and the organization's innovation and improvement activities-operational measures that are the drivers of future financial performance."

Apa yang menyebabkan konsep ini menarik ialah komponen dari scorecard didesain secara integratif sehingga masing-masing saling memperkuat satu sama lain dalam menunjukkan kondisi terkini dan kondisi perusahaan di masa yang akan datang (Chow et al, 2006).

Ukuran balanced scorecard adalah penjabaran dari visi dan strategi (Chow et al, 2006). Balanced Scorecard yang baik mengkombinasikan ukuran financial dari kinerja masa lalu perusahaan dengan ukuran dari kinerja perusahaan di masa yang akan datang. 
Pengukuran kinerja dalam Balanced Scorecard memandang unit bisnis dari empat perspektif yaitu perspektif keuangan, pelanggan, proses bisnis internal, dan proses pembelajaran dan pertumbuhan.

IT Balanced Scorecard. Pada tahun 1997, Van Grembergen dan Van Bruggen mengadopsi Balanced Scorecard (BSC) untuk digunakan dalam Departemen Teknologi Informasi pada perusahaan. Dalam pandangan mereka, Departemen Teknologi Informasi tersebut merupakan penyedia layanan internal, maka perspektif yang digunakan harus diubah dan disesuaikan. Melihat bahwa pengguna mereka adalah pegawai internal dan kontribusi mereka dinilai berdasarkan pihak manajemen, maka mereka mengajukan perubahan seperti yang terlihat pada gambar berikut.

BSC Tradisional

\section{IT Balanced Scorecard}

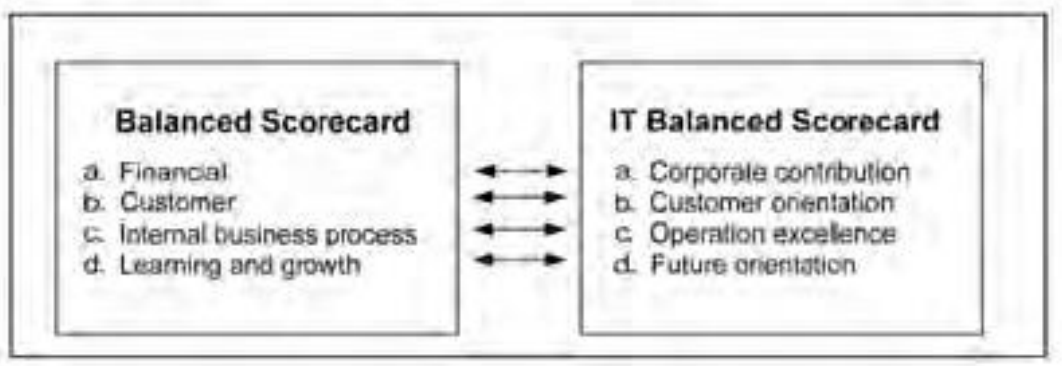

Gambar 1. Perubahan perspektif BSC Tradisional menjadi IT Balanced Scorecard

Masing-masing perspektif yang ada pada IT Balanced Scorecard dapat dijelaskan sebagai berikut :

1. Perspektif Kontribusi Perusahaan, mengevaluasi kinerja Divisi IT berdasarkan pandangan dari manajemen eksekutif, direktur dan shareholder. Merupakan nilai bisnis yang dibangun berkat investasi IT.

2. Perspektif Orientasi Pengguna, mengevaluasi kinerja IT berdasakarkan cara pandang pengguna (user) yang menggunakan. Lebih ke arah evaluasi user terhadap kinerja IT.

3. Perspektif Keunggulan Operasional, menilai kinerja IT berdasarkan efektivitas dan efisiensi dari proses-proses IT yang dinilai oleh pihak manajemen.

4. Perspektif Orientasi Masa Depan, menilai kinerja IT berdasarkan cara pandang Divisi IT itu sendiri terhadap tantangan di masa depan. Pada perspektif ini menunjukkan teknologi dan SDM sangat diperlukan Divisi IT untuk memberikan layanan tepat waktu.

IT Balanced Scorecard memiliki tujuan agar pada pengguna dapat menyesuaikan perencanaan dan aktivitas-aktivitas sitem informasi dengan tujuan dan kebutuhan organisasi, menyesuaikan usaha pengguna dengan tujuan sistem informasi, menyediakan pengukuran untuk mengevaluasi efektivitas organisasi sistem informasi, mendorong dan mempertahankan kinerja sistem informasi yang semakin meningkat, dan pencapaian hasil yang seimbang di antara kelompok stakeholder (Maula \& Ghozali, 2012).

\section{METODOLOGI PENELITIAN}

Jenis penelitian yang digunakan yaitu penelitian terapan. Hasil dari analisa akan digunakan untuk mendapatkan gambaran nilai dan memberikan masukan terhadap Divisi IT mengenai kinerjanya.

Penulis menggunakan data primer melalui wawancara kepada seorang pimpinan Divisi IT yang sangat mengetahui garis besar dari kegiatan IT dalam perusahaan. Wawancara didasarkan pada empat perspektif yang ada pada IT Balanced Scorecard yaitu Perspektif Kontribusi Perusahaan, Perspektif Terhadap Pengguna, Perspektif Penyempurnaan Operasional, dan Perspektif Orientasi Masa Depan. Wawancara dilakukan di dalam gedung perusahaan PT. XYZ. Selain itu juga digunakan data sekunder berupa visi misi IT, struktur 
organisasi, aplikasi yang digunakan, dan hal lainnya yang berhubungan dengan teknologi informasi.

Pengukuran diawali dengan melalukan penyelarasan visi, misi, strategi dari Divisi IT. Kegiatan ini untuk mengetahui tujuan sebenarnya dalam melakukan perencanaan kegiatan. Selanjutnya mendeskripsikan isi dari strategi Divisi IT dengan masing-masing perspektif IT Balanced Scorecard ke dalam diagram hubungan sebab akibat, agar memahami secara spesifik tujuan yang akan dicapai. Hasil dari wawancara kemudian dirangkum ke dalam tabel agar dapat dijadikam rekomendasi atau masukan untuk melakukan perbaikan, mempertahankan dan meningkatkan kinerja di waktu mendatang.

\section{HASIL DAN PEMBAHASAN}

1. Visi Divisi IT Support the Business Process

\section{Misi Divisi IT}

Mampu untuk proaktif dalam melihat apa yang menjadi kebutuhan perusahaan agar setiap unit kegiatan yang ada dapat berjalan dengan lancar tanpa kendala. Mulai dari menciptakan keunggulan melalui inovasi dan solusi yang baik, efektif, serta efisien.

\section{Tujuan Strategis dari KPI Divisi IT}

a. Uptime Sistem Jaringan Komputer, dengan tujuan untuk penyediaan fasilitas IT beserta sistem IT

b. SLA (Service Level Agreement), dengan tujuan untuk perbaikan hardware, software, maupun jaringan yang dapat diselesaikan sesuai waktu yang telah disepakati

c. Waktu pemenuhan kebutuhan user, dengan tujuan untuk memenuhi kebutuhan perangkat hardware yang akan digunakan user untuk kegiatan operasional.

d. Penyediaan Aplikasi (Software), dengan tujuan untuk mengetahui ketepatan dalam penyediaan aplikasi sesuai yang dibutuhkan oleh tiap-tiap divisi yang bersangkutan.

e. Jumlah cabang yang terkoneksi secara online ke pusat, dengan tujuan untuk mengetahui peningkatan keunggulan operasional. Dengan semakin banyaknya cabang yang terhubung, akan mempermudah IT dalam monitoring, maintenance, serta troubleshooting.

f. Pelatihan (training), dengan tujuan untuk meningkatkan keahlian dari personil divisi IT, sehingga ke depannya dapat mendukung dan memberikan solusi terbaik untuk kegiatan operasional perusahaan.

\section{Penyusunan Strategy Map Divisi IT}

Pada peta strategi Divisi IT, setiap unsur dari tiap perspektif mempunyai hubungan yang saling berkaitan satu sama lainnya. Setiap hubungan sebab akibat antara unsurunsur dalam masing-masing perspektif saling berkolerasi positif terhadap tercapainya kontribusi Divisi IT terhadap perusahaan. 


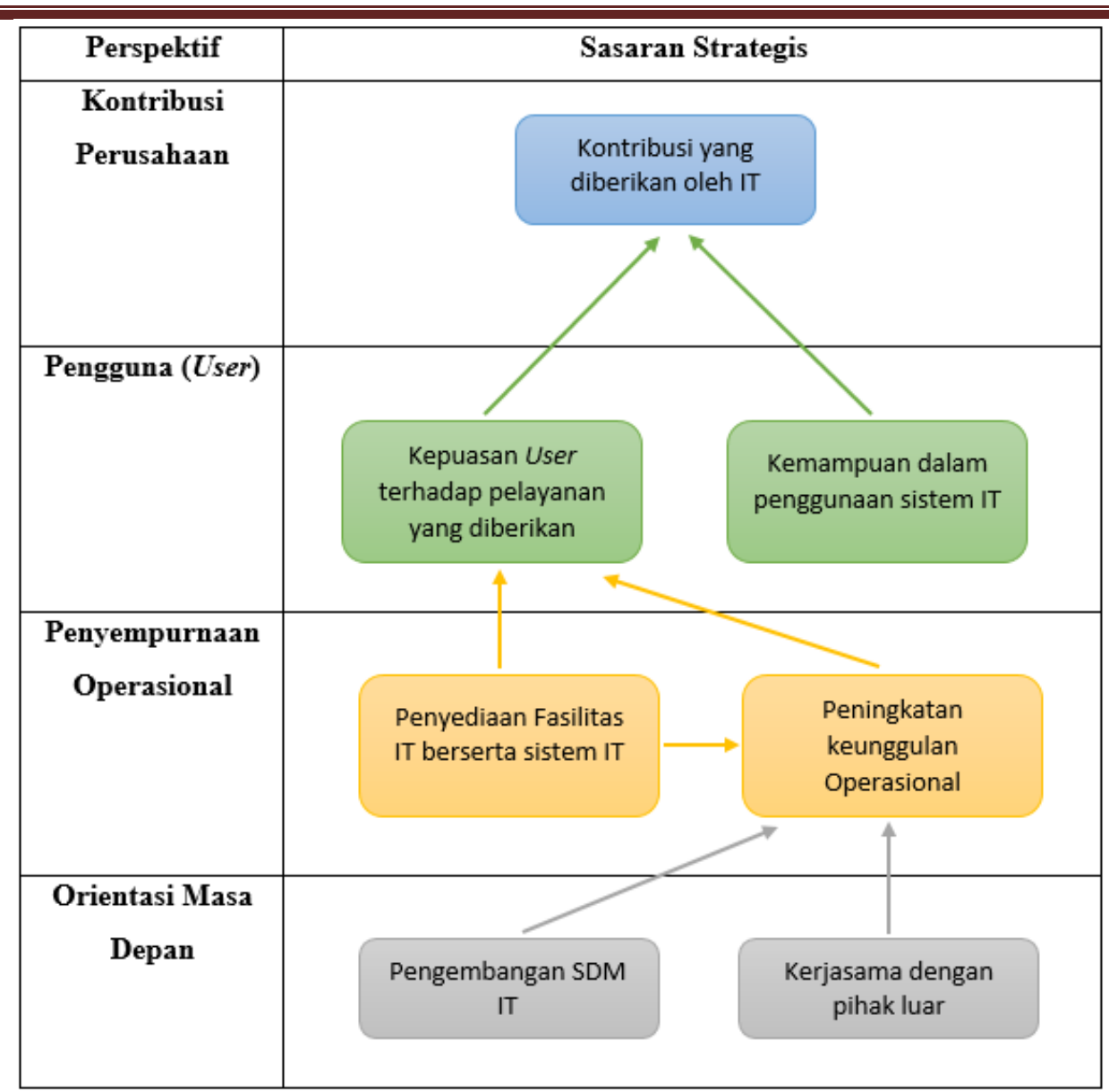

Gambar 2. Strategy Map Divisi IT

5. Sasaran dan Ukuran Strategis terhadap keempat perspektif IT BSC

a. Perspektif Kontribusi Terhadap Perusahaan

Perspektif Kontribusi Perusahaan

\begin{tabular}{|l|l|c|}
\hline \multicolumn{1}{|c|}{ Sasaran Strategis } & \multicolumn{1}{|c|}{ Ukuran Strategis } & Satuan \\
\hline $\begin{array}{l}\text { Kontribusi yang } \\
\text { diberikan oleh IT }\end{array}$ & $\begin{array}{l}\text {-Peningkatan kinerja dengan menggunakan } \\
\text { sistem computer }\end{array}$ & $\%$ \\
\hline
\end{tabular}

b. Perspektif Orientasi Pengguna

\begin{tabular}{|l|l|c|}
\hline \multicolumn{3}{|c|}{ Perspektif Orientasi Pengguna (User) } \\
\hline \multicolumn{1}{|c|}{ Sasaran Strategis } & \multicolumn{1}{|c|}{ Ukuran Strategis } & Satuan \\
\hline $\begin{array}{l}\text { Kepuasan User terhadap } \\
\text { pelayanan yang diberikan }\end{array}$ & $\begin{array}{l}\text {-Tingkat kepuasan Pengguna } \\
\text {-Tingkat komplain Pengguna }\end{array}$ & \\
\hline $\begin{array}{l}\text { Kemampuan dalam } \\
\text { penggunaan sistem IT }\end{array}$ & $\begin{array}{l}\text {-Jumlah } \text { user yang mampu untuk } \\
\text { menggunakan teknologi }\end{array}$ & Jumlah \\
\hline
\end{tabular}

c. Perspektif Penyempurnaan Operasional

\begin{tabular}{|l|l|c|}
\hline \multicolumn{3}{|c|}{ Perspektif Penyempurnaan Operasional } \\
\hline \multicolumn{1}{|c|}{ Sasaran Strategis } & \multicolumn{1}{|c|}{ Ukuran Strategis } & Satuan \\
\hline $\begin{array}{l}\text { Peningkatan Keunggulan } \\
\text { Operasional }\end{array}$ & -Efisiensi dan Efektivitas pekerjaan & $\%$ \\
\hline $\begin{array}{l}\text { Penyediaan Fasilitas IT } \\
\text { berserta sistem IT }\end{array}$ & $\begin{array}{l}\text {-Tingkat Pemenuhan sesuai kebutuhan } \\
\text { operasional }\end{array}$ & $\%$ \\
\hline
\end{tabular}

d. Perspektif Orientasi Masa Depan

\begin{tabular}{|c|c|c|}
\hline \multicolumn{3}{|c|}{ Perspektif Orientasi Masa Depan } \\
\hline Sasaran Strategis & Ukuran Strategis & Satuan \\
\hline Pengembangan SDM IT & -Pembelajaran dan Pelatihan SDM IT & $\%$ \\
\hline Kerjasama dengan pihak & -Jumlah kerjasama dengan pihak terkait & Jumlah \\
\hline
\end{tabular}


luar

\section{Rangkuman Hasil Analisa IT Balanced Scorecard}

Pada tabel di bawah ini merupakan rangkuman hasil analisa dari keempat perspektif yang ada dalam IT Balanced Scorecard.

\begin{tabular}{|c|c|}
\hline No. & Chen \\
\hline 1 & $\begin{array}{l}\text { IT memberikan kontribusi terhadap perusahaan berupa penyediaan komputer, } \\
\text { pemeliharaan jaringan internet dan intranet, kemudahan dalam melakukan } \\
\text { pekerjaan, mempercepat suatu proses pekerjaan, komunikasi antar site office } \\
\text { project dengan Head Office. }\end{array}$ \\
\hline \multirow[t]{2}{*}{2} & $\begin{array}{l}\text { Daru sisi nilai bisnis, aplikasi dan teknologi IT yang dikelola oleh divisi IT } \\
\text { dapat menghemat waktu dan juga tenaga kerja yang ada, seperti monitoring } \\
\text { pekerjaan pada site office project melalui CCTV. Penggunaan Absensi } \\
\text { Finger yang terhubung secara terpusat menggunakan intranet, sehingga bisa } \\
\text { ditarik ke pusat walaupun lokasinya berbeda. }\end{array}$ \\
\hline & Perspek \\
\hline 1 & $\begin{array}{l}\text { IT beser } \\
\text { pekerjaan }\end{array}$ \\
\hline 2 & pengguna, \\
\hline \multirow[t]{2}{*}{3} & $\begin{array}{l}\text { kan IT mar } \\
\text { nen, sehing }\end{array}$ \\
\hline & al \\
\hline 1 & adi dap \\
\hline 2 & gkat kerja seperti komputer, \\
\hline \multirow[t]{2}{*}{3} & $\begin{array}{l}\text { ya, karena teknologi informasi yang } \\
\text { ga sistem yang tersentralisasi untuk } \\
\text { aksi operasional perusahaan. }\end{array}$ \\
\hline & Perspekti \\
\hline 1 & Dibutuhkan program training tertuli \\
\hline 2 & $\begin{array}{l}\text { Perlu beberapa orang yang menguasai bidang tertentu seperti keamanan } \\
\text { jaringan, keamanan web, menguasai linux, oracle dan sebagainya untuk } \\
\text { mengembangkan perusahaan ke depannya. }\end{array}$ \\
\hline 3 & $\begin{array}{l}\text { at me } \\
\text { ai. }\end{array}$ \\
\hline
\end{tabular}

\section{KESIMPULAN DAN SARAN}

\section{Kesimpulan}

Berdasarkan penelitian yang telah dilakukan, dapat disimpulkan beberapa hal sebagai berikut:

1. Penilaian kinerja yang dilakukan oleh PT. XYZ menggunakan IT Balanced Scorecard berdasarkan empat perspektif yaitu perspektif kontribusi perusahaan, perspektif orientasi pengguna, perspektif penyempurnaan operasional, dan perspektif orientasi masa depan.

2. Divisi IT mempunyai kinerja yang dapat mempengaruhi perkembangan perusahaan. Hal ini dapat dilihat pada sasaran strategis IT dan juga hubungan sebab akibat dalam IT Balanced Scorecard yang dirancang. Setiap kegiatan yang dilakukan Divisi IT bertujuan untuk mendukung kegiatan operasional perusahaan, mulai dari persediaan PC (hardware), Sistem Aplikasi (software), Jaringan, pemecahan masalah (troubleshooting), dan alat pendukung lainnya. 


\section{Saran}

Berdasarkan dari penelitian yang telah dilakukan, terdapat beberapa saran yang disampaikan sebagai bahan pertimbangan bagi perusahaan yaitu:

1. IT Balanced Scorecard hanya menilai divisi IT dalam perusahaan. Untuk mengetahui kinerja perusahaan keseluruhan, disarankan untuk menggunakan Balanced Scorecard dengan empat perspektif yaitu Perspektif Keuangan, Perspektif Pelanggan, Perspektif Bisnis Internal, dan Perspektif Pertumbuhan dan Pembelajaran.

2. Diharapkan divisi IT dapat terus berkembang, berinovasi, dan mengikuti perkembangan teknologi, sehingga dapat memberikan kontribusi yang memuaskan dan sesuai dengan harapan perusahaan.

\section{DAFTAR PUSTAKA}

Grembergen, W. V. and R. V. Bruggen. (1997). "Measuring and improving corporate Information Technology through the balanced scorecard technique", in Proceedings of the European Conference on Information Technology, Delft, The Netherlands.

Grembergen, W. V, R. Saull. (2001). Information Technology Governance through the Balanced Scorecard. In W. Van Grembergen (Ed.), Information Technology Evaluation Methods \& Management. Hershey, Pennyslvania: Idea Group Publishing.

Grembergen, W. V, R. Saull, and S. D. Haes (2003) "Linking the IT Balanced Scorecard to the Business Objectives at a Major Canadian Financial Group", Journal of Information Technology cases and applications.

Kaplan Robert. S. and Norton D. P. (1996a). The Balanced Scorecard: Translating Strategy into Action. Boston, Mass; Harvard Business School Press.

Kaplan, Robert S. dan Norton D.P. (2000). Balanced Scorecard: Menerapkan Strategi Menjadi Aksi. Erlangga, Jakarta.

Kaplan S. Robert, dan David P. Norton. (2009). The Balanced Scorecard: Translating Strategy into Action. Kindle Edition. Massachusetts: Harvard Business School Press.

Mulyadi. (2001). Balanced Scorecard : Alat Manajemen Kontemporer Untuk Pelipatgandaan Kinerja Keuangan Perusahaan, Edisi Pertama, Salemba Empat, Jakarta.

Mulyadi. (2007). Sistem Perencanaan dan Pengendalian Manajemen, Salemba Empat, Jakarta.

Swierk, Joanna. And Mulawa, Magdalena. (2014). IT Balanced Scorecard as a Significant Component of Competitive and Modern Company. Journal Management Knowledge and Learning of International Conference.

The Balanced Scorecard and IT Governance. (2000).

Retrieved from http://www.isaca.org/Journal/Past-Issues/2000/Volume-2/Pages/The-

Balanced-Scorecardand-IT-Governance.aspx

The IT Balanced Scorecard - A Roadmap to Effective Governance of a Shared Services IT Organization. (2000).

Retrieved from http://www.isaca.org/Journal/Past-Issues/2000/Volume-2/Pages/TheIT-Balanced-Scorecard-A-Roadmap-to-Effective-Governance-of-a-Shared-ServicesIT-Organization.aspx 


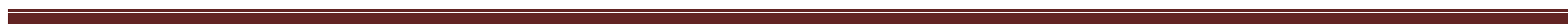
$\cdot$ 